Vincent BERNAUDEAU, Jean-Pierre NANDRIN, Bénédicte ROCHET, Xavier ROUSSEAUX et Axel TIXHON (dir.), Les praticiens du droit du Moyen Âge à l'époque contemporaine. Approches prosopographiques (Belgique, Canada, France, Italie, Prusse)

Rennes, Presses universitaires de Rennes, 2008, 351 p., ISBN

978-2-7535-0578-0, $19 €$

\title{
Jean Bart
}

\section{(2) OpenEdition}

\section{Édition électronique}

URL : https://journals.openedition.org/ahrf/11571

DOI : 10.4000/ahrf.11571

ISSN : 1952-403X

\section{Éditeur :}

Armand Colin, Société des études robespierristes

\section{Édition imprimée}

Date de publication : 1 octobre 2009

Pagination : 189-190

ISBN : 978-2-200-92560-4

ISSN : 0003-4436

\section{Référence électronique}

Jean Bart, « Vincent bernaudeau, Jean-Pierre nandrin, Bénédicte rochet, Xavier rousseaux et Axel tixhon (dir.), Les praticiens du droit du Moyen Âge à l'époque contemporaine. Approches prosopographiques (Belgique, Canada, France, Italie, Prusse) », Annales historiques de la Révolution française [En ligne], 358 | octobre-décembre 2009, mis en ligne le 29 juillet 2010, consulté le 22 avril 2022. URL : http:// journals.openedition.org/ahrf/11571 ; DOI : https://doi.org/10.4000/ahrf.11571 
Vincent BERNAUDEAU, Jean-Pierre NANDRIN, Bénédicte ROCHET, Xavier ROUSSEAUX et Axel TIXHON (dir.), Les praticiens du droit du Moyen Âge à l'époque contemporaine. Approches prosopographiques (Belgique, Canada, France, Italie, Prusse)

Rennes, Presses universitaires de Rennes, 2008, 351 p., ISBN

978-2-7535-0578-0, $19 €$

Jean Bart

\section{RÉFÉRENCE}

Vincent BERNAUDEAU, Jean-Pierre NANDRIN, Bénédicte ROCHET, Xavier RouSSEAUX et Axel TIXHON (dir.), Les praticiens du droit du Moyen Âge à l'époque contemporaine. Approches prosopographiques (Belgique, Canada, France, Italie, Prusse), Rennes, Presses universitaires de Rennes, 2008, 351 p., ISBN 978-2-7535-0578-0, $19 €$

La publication des actes du colloque tenu à Namur en décembre 2006 suscite les mêmes remarques que celle des travaux du colloque de Québec de septembre 2004 (cf. AHRF, $\mathrm{n}^{\circ} 350$, oct./déc. 2007, p. 185-186), tenant tant à l'amplitude de la chronologie: du milieu du Moyen Âge au XX $X^{e}$ siècle, qu'à la diversité géographique des lieux de recherche : du Canada à la Prusse en passant par la Belgique, la France et l'Italie. Des liens aussi ténus que ceux qui unissent l'étude des notaires canadiens du XVIII siècle et celle des premiers juges des enfants en France - pour ne prendre que deux exemples - 
ne rendent-ils pas acrobatique toute comparaison féconde? L'élément unitaire d'une telle recherche collective est certes la démarche prosopographique, et réside donc avant tout dans la définition d'une méthode commune. Mais n'aurait-il pas été bon de définir préalablement l'emploi du mot «praticien »? En quoi les «praticiens » sont-ils différents des «auxiliaires de la justice », objets du colloque précédent ? D'autant que, pour les initiateurs du colloque, les « praticiens du droit » forment un « large éventail » regroupant «les personnes qui occupent des fonctions, charges ou offices correspondant à l'exercice d'une prérogative de souveraineté, et celles qui sont à même d'assurer des fonctions de représentation ou de défense, de rédiger des actes et de participer de manière plus ou moins formelle à l'œuvre de justice» (introduction). N'est-ce point là une acception trop large ? Convient-il de faire entrer les magistrats - à quelque époque que ce soit - dans la catégorie des praticiens? La question mériterait d'être au moins posée et discutée, surtout dans une perspective prosopographique, même si les distances sociales ne sont pas toujours aussi tranchées que du temps de La Bruyère qui distinguait bien "le vil praticien, [...] au fond de son étude sombre et enfumée, et l'esprit occupé d'une plus noire chicane » et les «jeunes magistrats que les grands biens et les plaisirs ont associé à quelques uns de ceux que l'on nomme à la cour de petits maîtres [...]»(Caract. De la ville). Même lorsque les distinctions socioéconomiques sont moins tranchées, il semble difficile, d'un point de vue juridique, d'assimiler ceux qui exercent au nom du souverain - prince, roi, nation ou peuple -, la fonction de rendre la justice - de dire ce qui est juste - et ceux qui connaissent simplement les arcanes de la procédure ou de la rédaction des actes authentiques.

Parmi une vingtaine d'articles composant ce livre dédié à la mémoire du regretté Jacques Logie qui participait activement aux colloques d'histoire des institutions judiciaires de l'époque révolutionnaire, deux contributions portant sur cette période retiendront surtout l'attention des lecteurs de notre revue : celles de Pierre-Jean NIEBES, «Profils de juges de paix du département de Jemmapes du Directoire à l'Empire (1795-1814) », et de Christian CHÊNE, « Pigeau et Bellard : la formation des praticiens du droit de la fin de l'Ancien Régime à la Restauration ». 